\title{
Short Communication: Estimates of Genetic Variation of Milk Fatty Acids in US Holstein Cows ${ }^{1}$
}

\author{
G. Bobe ${ }^{\star 2}$ J. A. Minick Bormann, $\dagger$ G. L. Lindberg, ${ }^{*}$ A. E. Freeman, $\neq$ and D. C. Beitz ${ }^{* 3}$ \\ *Nutritional Physiology, Department of Animal Science, lowa State University, Ames 50011 \\ †Department of Animal Science and Industry, Kansas State University, Manhattan 66506 \\ $\ddagger$ Animal Breeding and Genetics, Department of Animal Science, lowa State University, Ames 50011
}

\begin{abstract}
Interest in changing the milk fatty acid profile is growing. However, little is known about the genetic variability of milk fatty acids in the US Holstein population. Therefore, genetic parameters for milk fatty acids were estimated using a single-trait, mixed, linear animal model on 592 individual milk samples from 233 daughters of 53 sires in a cow herd genetically representative of the US Holstein population. Heritability $\left(\mathrm{h}^{2}\right)$ and repeatability $(\mathrm{r})$ estimates \pm standard errors for yields of individual fatty acids ranged from $0.00 \pm 0.08$ (C4:0) to $0.43 \pm 0.13$ (C12:0) for heritabilities and from $0.21 \pm 0.05$ (C18:1) to $0.43 \pm 0.05(\mathrm{C} 12: 0)$ for repeatabilities. Saturated $\left(h^{2}=0.23 \pm 0.12 ; \mathrm{r}=0.36 \pm 0.05\right)$ and de novo synthesized fatty acids $\left(\mathrm{C} 6: 0\right.$ to $\mathrm{C} 14: 0 ; \mathrm{h}^{2}=0.30$ $\pm 0.13 ; r=0.40 \pm 0.05$ ) had numerically higher estimates than did monounsaturated $\left(\mathrm{h}^{2}=0.09 \pm 0.09 ; \mathrm{r}=0.22\right.$ $\pm 0.05)$ and polyunsaturated fatty acids $\left(\mathrm{h}^{2}=0.08 \pm\right.$ $0.09 ; \mathrm{r}=0.27 \pm 0.05$ ). For relative proportions of individual fatty acids, the greatest heritability and repeatability estimates were obtained for $\mathrm{C} 8: 0\left(\mathrm{~h}^{2}=0.18 \pm 0.12\right.$; $\mathrm{r}=0.36 \pm 0.05), \mathrm{C} 10: 0\left(\mathrm{~h}^{2}=0.22 \pm 0.13 ; \mathrm{r}=0.46 \pm 0.05\right)$, $\mathrm{C} 12: 0\left(\mathrm{~h}^{2}=0.18 \pm 0.12 ; \mathrm{r}=0.46 \pm 0.05\right), \mathrm{C} 16: 0\left(\mathrm{~h}^{2}=\right.$ $0.09 \pm 0.12 ; \mathrm{r}=0.48 \pm 0.05), \mathrm{C} 16: 1\left(\mathrm{~h}^{2}=0.49 \pm 0.13\right.$; $\mathrm{r}=0.49 \pm 0.05)$, and $\mathrm{C} 18: 0\left(\mathrm{~h}^{2}=0.24 \pm 0.11 ; \mathrm{r}=0.39\right.$ \pm 0.05 ). Our results suggest the existence of genetic variability of milk fatty acids, in particular of mediumand long-chain fatty acids (C8:0 to C18:0), which could be used to improve the nutritional and textural properties of milk fat by selective breeding.
\end{abstract}

Key words: dairy cow, genetic variation, heritability, milk fatty acid

\footnotetext{
Received April 2, 2007.

Accepted November 11, 2007.

${ }^{1}$ Publication of the Iowa Agriculture and Home Economics Experiment Station, Ames, Project Number 3801.

${ }^{2}$ Present address: Cancer Prevention Fellowship Program, Office of Preventive Oncology, National Cancer Institute, National Institutes of Health, Bethesda, MD 20892; e-mail: bobeg@mail.nih.gov.

${ }^{3}$ Corresponding author: dcbeitz@iastate.edu
}

Typical milk fat of cows comprises $70 \%$ saturated, $25 \%$ monounsaturated, and 5\% polyunsaturated fatty acids (Grummer, 1991). A concern to consumers of dairy products is the high ratio of saturated to unsaturated fatty acids because of the linkage between intake of saturated fatty acids and various biological markers for cardiovascular disease risk in humans, including elevated blood pressure, insulin resistance, and hyperlipidemia, particularly of low-density lipoprotein cholesterol (Vessby et al., 2001; Sacks and Katan, 2002; Mensink et al., 2003; Rasmussen et al., 2006). Cow nutrition has been used primarily to alter milk fatty acid composition (Palmquist et al., 1993; Henning et al., 2006). Feeding cows rumen-protected unsaturated lipids decreases the proportion of saturated fatty acids, specifically myristic (C14:0) and palmitic acid (C16:0), in dairy products, which results in decreased serum total and low-density lipoprotein cholesterol in humans consuming the modified dairy products (Noakes et al., 1996; Poppitt et al., 2002).

Genetic selection has been proposed to alter milk fatty acid composition (Palmquist et al., 1993; Soyeurt et al., 2006). Differences in milk fatty acid profiles within and across cattle breeds have been reported (DePeters et al., 1995; Kelsey et al., 2003; Auldist et al., 2004; Soyeurt et al., 2006). Less is known about the genetic variability of milk fatty acids within breeds. Studies that estimated sources of genetic variation of milk fatty acids were conducted in Europe several decades ago, and none of the studies used an animal model (Edwards et al., 1973; Renner and Kosmack, 1974; Karijord et al., 1982; Syrstad et al., 1982). Thus, the objective of this study was to estimate sources of genetic variation of milk fatty acids in US Holstein cows by using a single-trait, linear animal model. We hypothesized that fatty acids that are synthesized de novo in the mammary gland (C6:0 to C14:0 and partly C16:0; Palmquist et al., 1993) have significant genetic variation and, therefore, have the potential to be altered by genetic selection.

Monthly (from August 1993 to July 1994), milk samples (each sample consisted of milk taken from one 
morning and one evening milking in equal amounts) were collected from each lactating Holstein cow (24 to 144 mo of age, 1 to 10 lactations) at the Iowa State University Dairy Breeding Research Facility (Ankeny, IA). For fatty acid analysis, a representative subset of milk samples was selected (Bobe et al., 2007). The sampled herd comprised 2 genetic lines (high and average milk PTA), and sires are genetically representative of the US population (Bobe et al., 2007). Details about cow management and chemical analyses of milk samples have been described previously (Bobe et al., 2007).

Raw means for yields, concentrations, and relative proportions of milk fatty acids were obtained using PROC MEANS of SAS (version 9.1.3; SAS Institute, 2002). The phenotypic and genetic variation for yields, concentrations, and relative proportions of milk fatty acids were estimated by using a single-trait, mixed linear animal model:

$$
\begin{gathered}
\mathbf{Y}_{\mathrm{ijklmno}}=\text { Parity }_{\mathbf{i}}+\mathbf{S C}_{\mathbf{j}}+\mathbf{L S}_{\mathbf{k}}+\mathbf{S M}_{\mathbf{l}}+\text { Diet }_{\mathrm{m}} \\
+\mathbf{S C C G}_{\mathbf{n}}+\mathbf{Z}_{1} \mathbf{a}_{\mathrm{o}}+\mathbf{Z}_{2} \mathbf{p e}_{\mathrm{o}}+\mathbf{e}_{\mathrm{ijklmno}},
\end{gathered}
$$

where $\mathbf{Y}_{\mathbf{i j k l m n o}}=$ vector of 592 daily milk records (e.g., milk fatty acid yield expressed in g/d, milk fatty acid concentration expressed in $\mathrm{g} / \mathrm{L}$, and relative proportion of a milk fatty acid expressed as weight $\%$ of an individual milk fatty acid to total milk fatty acids). The dependent variables were distributed normally. The independent fixed effects were: 3 parity groups ( $i=1,2$ and 3 , and $>3$ ); $\mathbf{S C}$ was 7 season of calving groups $(\mathrm{j}=$ winter 1992, spring 1993, ..., summer 1994); LS was lactation stage $(\mathrm{k}=1,2, \ldots, 10$, and $>10$ mo postpartum); SM was year-month of sampling ( 1 = August 1993, September 1993, ..., July 1994); 3 diet groups ( $\mathrm{m}=$ high, medium, and low lactational performance level); and SCCG was SCC group $(\mathrm{n}=<250,000,250,000$ $1,000,000$, and $>1,000,000$ cells $/ \mathrm{mL}$ SCC). The matrices $\mathbf{Z}_{1}$ and $\mathbf{Z}_{2}$ were incidence matrices for the random additive genetic (a) and permanent environmental (pe) effects of the cow 0 , respectively. The random residual effect for each milk record is $\mathbf{e}_{\mathbf{i j k l m n o}}$. In addition to animals with records, 53 sires, 132 dams, 92 grandsires, and 206 granddams without production records were included in the relationship matrix as well. All fixed effects and their classifications contributed significantly to the model.

The additive genetic, permanent environmental, and residual variances for yields, concentrations, and relative proportions of milk fatty acids were estimated iteratively via derivative-free REML in MTDFREML (Boldman et al., 1995). The convergence criterion for the variance component estimates was $10^{-9}$. Heritabilities were estimated from the ratio of $\sigma_{a}^{2}$ to the sum of $\sigma_{a}^{2}$, $\sigma_{p e}^{2}$, and $\sigma_{e}^{2}$. Repeatabilities were estimated from the ratio of the sum of $\sigma_{a}^{2}$ and $\sigma_{p \mathrm{e}}^{2}$ to the sum of $\sigma_{a}^{2}, \sigma_{p \mathrm{e}}^{2}$, and $\sigma_{e}^{2}$. Standard errors were estimated by the delta method (Dodenhoff et al., 1998). Variances were assumed to be the same for the various stages of lactation.

The estimates of phenotypic variation for yields, concentrations, and relative proportions of individual milk fatty acids and groups of milk fatty acids were large (Table 1), which is consistent with literature values (Kelsey et al., 2003; Auldist et al., 2004; Soyeurt et al., 2006). The relative proportions of saturated fatty acids ranged from 47.15 to $77.90 \%$, the relative proportions of monounsaturated fatty acids ranged from 18.67 to $48.56 \%$, and the relative proportion of polyunsaturated fatty acids ranged from 1.73 to $4.91 \%$. According to the Wisconsin Milk Marketing Board Milk Fat Roundtable (1988), the ideal nutritional milk fat would contain up to $8 \%$ saturated fatty acids and less than $10 \%$ polyunsaturated fatty acids, with the remaining fatty acids being monounsaturated fatty acids (O'Donnell, 1989). Although the difference between the least saturated milk fat in this study and the ideal milk fat is large, the results indicate that some cows produce milk fat with a more desirable (nutritionally) fatty acid profile.

The heritability and repeatability estimates for daily yields of individual milk fatty acids were low to moderate and ranged from $0.00(\mathrm{C} 4: 0)$ to $0.43(\mathrm{C} 12: 0)$ for heritability estimates $\left(\mathbf{h}^{2}\right)$ and from 0.21 (C18:1) to 0.43 (C12:0) for repeatability estimates (r) (Table 2). Moderate heritability and repeatability estimates were also obtained for C8:0 $\left(h^{2}=0.27 ; \mathrm{r}=0.38\right), \mathrm{C} 10: 0\left(\mathrm{~h}^{2}=0.42\right.$; $\mathrm{r}=0.42), \mathrm{C} 12: 0\left(\mathrm{~h}^{2}=0.43 ; \mathrm{r}=0.43\right)$, and $\mathrm{C} 14: 0\left(\mathrm{~h}^{2}=\right.$ $0.26 ; \mathrm{r}=0.40$ ). These are the first reported heritability and repeatability estimates for daily yields of individual fatty acids in cows. Heritability and repeatability estimates for daily yields of saturated fatty acids $\left(\mathrm{h}^{2}=0.23\right.$; $\mathrm{r}=0.36)$ and fatty acids synthesized de novo in the mammary gland (C6:0 to $\left.\mathrm{C} 14: 0 ; \mathrm{h}^{2}=0.30 ; \mathrm{r}=0.40\right)$ were numerically higher than were the estimates for monounsaturated fatty acids $\left(\mathrm{h}^{2}=0.09 ; \mathrm{r}=0.22\right)$ and polyunsaturated fatty acids $\left(h^{2}=0.08 ; r=0.27\right.$; Table 2 ). This result is consistent with our hypothesis that milk fatty acids that are primarily synthesized de novo in the mammary gland (C6:0 to C14:0; Palmquist et al., 1993) have significant genetic variation. Milk fatty acids that are derived primarily from the diet (C4:0, unsaturated fatty acids; Palmquist et al., 1993) had nonsignificant, low heritability estimates (Table 2). Our results are similar to the only reported heritability estimates for daily yield of milk fatty acid groups, which are 0.34 for C4:0 to C8:0, 0.22 for C10:0 to C16:0, and 0.03 for C18:0 to C18:3 (Renner and Kosmack, 1974). In summary, our results suggest that daily yields of 
Table 1. Mean, SD, and range (minimum and maximum) for yield, concentration, and relative proportion of milk fatty acids (FA) in US Holstein cows ${ }^{1}$

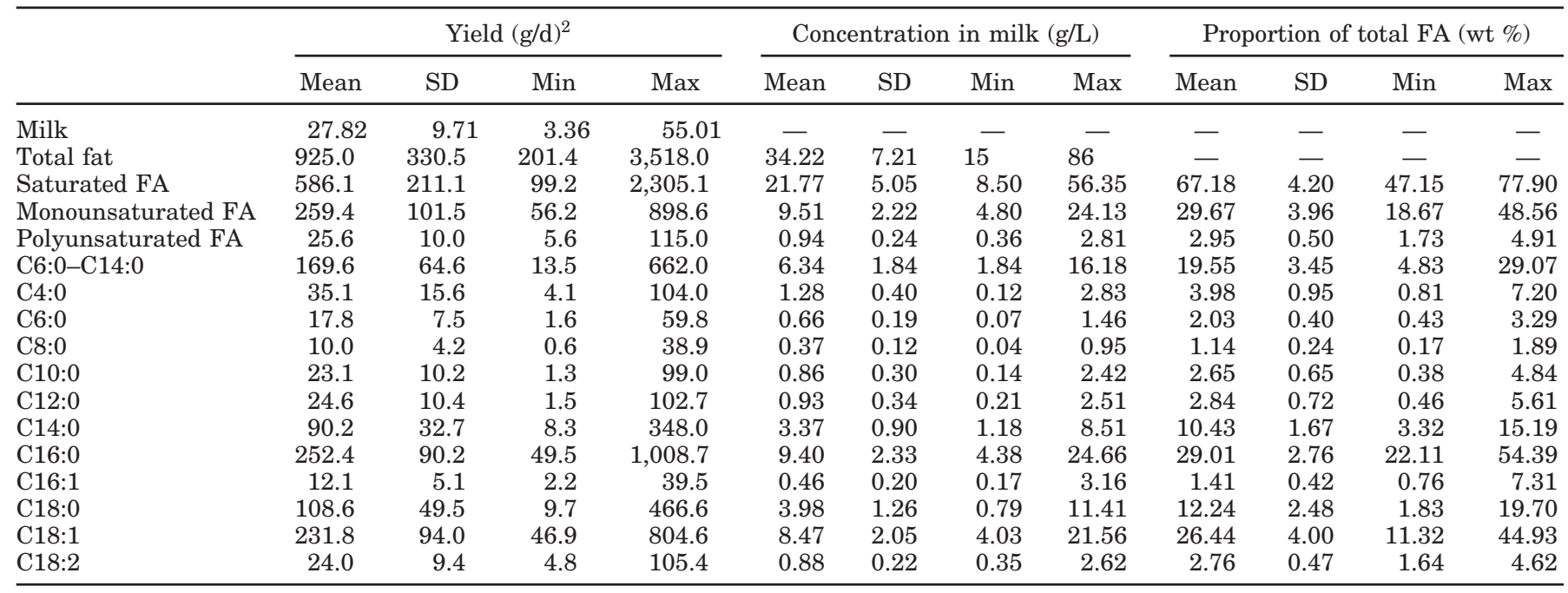

${ }^{1} 592$ daily samples from 233 cows of 53 sires.

${ }^{2}$ Units of measure of all variables were $\mathrm{g} / \mathrm{d}$, except for milk measured in $\mathrm{kg} / \mathrm{d}$.

most individual milk fatty acids that are synthesized in the mammary gland have moderate genetic variation.

The heritability and repeatability estimates for daily yield and concentrations of milk fatty acids followed similar trends (Table 2). For heritabilities, our estimates were similar to those reported by Renner and Kosmack (1974) in German cattle and Syrstad et al. (1982) in Norwegian cattle. For repeatabilities, our estimates were similar to those reported by Soyeurt et al.
(2006) in Belgian cattle and higher than those reported by Syrstad et al. (1982).

For relative proportions of fatty acids, the heritability estimates for individual fatty acids were small to moderate (Table 2). Low estimates were obtained for C4:0 $\left(h^{2}=0.00\right)$, C6:0 $\left(h^{2}=0.00\right), C 14: 0\left(h^{2}=0.00\right), C 18: 1$ $\left(h^{2}=0.06\right)$, and C18:2 $\left(h^{2}=0.00\right)$, and moderate estimates were obtained for C12:0 $\left(\mathrm{h}^{2}=0.18\right), \mathrm{C} 16: 1\left(\mathrm{~h}^{2}=\right.$ 0.49 ), and C18:0 $\left(h^{2}=0.24\right)$. Edwards et al. (1973) ob-

Table 2. Genetic parameter estimates (mean \pm SE) for yield, concentration, and relative proportion of milk fatty acids (FA) in US Holstein cows $^{1}$

\begin{tabular}{|c|c|c|c|c|c|c|}
\hline & \multicolumn{2}{|c|}{ Yield $(\mathrm{g} / \mathrm{d})^{2}$} & \multicolumn{2}{|c|}{ Concentration in milk (g/L) } & \multicolumn{2}{|c|}{ Proportion of total FA (wt\%) } \\
\hline & Heritability & Repeatability & Heritability & Repeatability & Heritability & Repeatability \\
\hline Milk & $0.11 \pm 0.12$ & $0.58 \pm 0.04^{* *}$ & - & - & - & - \\
\hline Saturated FA & $0.23 \pm 0.12$ & $0.36 \pm 0.05^{* *}$ & $0.27 \pm 0.12^{*}$ & $0.44 \pm 0.05^{* *}$ & $0.05 \pm 0.10$ & $0.43 \pm 0.05^{* *}$ \\
\hline Monounsaturated FA & $0.09 \pm 0.09$ & $0.22 \pm 0.05^{* *}$ & $0.09 \pm 0.08$ & $0.09 \pm 0.05$ & $0.08 \pm 0.10$ & $0.39 \pm 0.05^{*}$ \\
\hline Polyunsaturated FA & $0.08 \pm 0.09$ & $0.27 \pm 0.05^{* *}$ & $0.25 \pm 0.11 *$ & $0.25 \pm 0.06^{* *}$ & $0.00 \pm 0.11$ & $0.49 \pm 0.05 *$ \\
\hline C6:0-C14:0 & $0.30 \pm 0.13^{*}$ & $0.41 \pm 0.05^{* *}$ & $0.28 \pm 0.13^{*}$ & $0.51 \pm 0.05^{* *}$ & $0.04 \pm 0.09$ & $0.35 \pm 0.05^{* *}$ \\
\hline $\mathrm{C} 8: 0$ & $0.27 \pm 0.13^{*}$ & $0.38 \pm 0.05^{* *}$ & $0.37 \pm 0.14^{* *}$ & $0.51 \pm 0.05^{* *}$ & $0.18 \pm 0.12$ & $0.36 \pm 0.05^{* *}$ \\
\hline C10:0 & $0.42 \pm 0.13^{* *}$ & $0.42 \pm 0.05^{* *}$ & $0.40 \pm 0.14^{* *}$ & $0.55 \pm 0.05^{* *}$ & $0.22 \pm 0.13$ & $0.46 \pm 0.05^{* *}$ \\
\hline C12:0 & $0.43 \pm 0.13^{* *}$ & $0.43 \pm 0.05^{* *}$ & $0.36 \pm 0.13^{* *}$ & $0.55 \pm 0.05^{* *}$ & $0.18 \pm 0.12$ & $0.46 \pm 0.05^{* *}$ \\
\hline C14:0 & $0.26 \pm 0.13^{*}$ & $0.40 \pm 0.05^{* *}$ & $0.18 \pm 0.12$ & $0.47 \pm 0.05^{* *}$ & $0.00 \pm 0.08$ & $0.29 \pm 0.05^{* *}$ \\
\hline C16:0 & $0.22 \pm 0.12$ & $0.38 \pm 0.05^{* *}$ & $0.20 \pm 0.12$ & $0.44 \pm 0.05^{* *}$ & $0.09 \pm 0.12$ & $0.48 \pm 0.05^{* *}$ \\
\hline C16:1 & $0.23 \pm 0.11^{*}$ & $0.32 \pm 0.05^{* *}$ & $0.34 \pm 0.13^{* *}$ & $0.34 \pm 0.06^{* *}$ & $0.49 \pm 0.13^{* *}$ & $0.49 \pm 0.05^{* *}$ \\
\hline C18:0 & $0.14 \pm 0.09$ & $0.24 \pm 0.06^{* *}$ & - & $0.29 \pm 0.06^{* *}$ & $0.24 \pm 0.11^{*}$ & $0.39 \pm 0.05^{* *}$ \\
\hline
\end{tabular}

${ }^{1} 592$ daily samples from 233 cows of 53 sires.

${ }^{2}$ Units of measure were $\mathrm{g} / \mathrm{d}$, except for milk measured in $\mathrm{kg} / \mathrm{d}$.

$* P \leq 0.05 ; * * P \leq 0.01$. 
tained heritability estimates between $0.64(\mathrm{C} 12: 0)$ and 0.95 (C18:0) in an Ayrshire twin cow study in the United Kingdom, but those results were subject to overestimation because of the study design. Our estimates are similar in magnitude to those obtained by Renner and Kosmack (1974) and Karijord et al. (1982). Therefore, we conclude that there is additive genetic variability for milk fatty acid composition between US Holstein cows.

The repeatability estimates for the relative proportions of most individual fatty acids are more than twice as high as the heritability estimates and range from $0.07(\mathrm{C} 4: 0)$ to $0.49(\mathrm{C} 16: 1)$ with most being between 0.35 and 0.49 , which is close to those obtained by Soyeurt et al. (2006). Again, Karijord et al. (1982) reported repeatability estimates slightly lower than ours. The coefficients of variation $(\mathbf{C V})$ of individual milk fatty acids ranged from $9.5 \%(\mathrm{C} 16: 0)$ and $29.8 \%(\mathrm{C} 16: 1)$ with $\mathrm{C} 16: 0$ being the only fatty acid with a CV below $15 \%$ (Table 1). Other milk fatty acids with high CV were C10:0 $(\mathrm{CV}=24.5 \%)$ and $\mathrm{C} 12: 0(\mathrm{CV}=25.4 \%)$. Given the considerable phenotypic and genetic variation in milk fatty acid composition, our results suggest that it might be feasible to alter the milk fatty acid profile by genetic selection.

There are several potential limitations to our genetic estimates. Multiparous cows were included in the analysis, which could introduce bias because culling based on milk yield might affect milk fatty acid composition. However, we reported, for the same data set, that selection for milk yield had little effect on milk fatty acid composition (Bobe et al., 2007). One has to take into consideration that this study was based on a limited number of cows with a relationship matrix based on 2 generations, and, thus, genetic estimates have large standard errors (Tables 2), which limits reaching definite conclusions about the genetic potential to alter milk fatty acid composition in the US Holstein population. Genetic estimates for milk fatty acids in US Holstein cows, however, are not available.

In conclusion, this study demonstrated differences in yields, concentrations, and relative proportions of individual milk fatty acids between US Holstein cows. The genetic parameter estimates partially infer genetic variability in yields, concentrations, and relative proportions of individual milk fatty acids, in particular in medium- and long-chain fatty acids (C8:0 to C18:0). Genetic variability in yields and relative proportions of individual milk fatty acids would provide an opportunity to alter milk fatty acid composition by selective breeding for individual or groups of fatty acids.

\section{ACKNOWLEDGMENTS}

The authors thank Swiss Valley Farms (Davenport, IA) for analysis of milk samples, J. W. Young for edito- rial assistance, D. H. Kelley for coordination of milk sampling, and G. Cooling and C. Sharp for laboratory assistance. The project was supported by the USDA Center for Designing Foods to Improve Nutrition (Ames, IA) and by the Royal Dutch Cattle Syndicate (Arnhem, Netherlands). Gerd Bobe was supported in part by a scholarship from the National Milk Producers Federation (Arlington, VA).

\section{REFERENCES}

Auldist, M. J., K. A. Johnston, N. J. White, W. P. Fitzsimons, and M. J. Boland. 2004. A comparison of the composition, coagulation characteristics and cheesemaking capacity of milk from Friesian and Jersey dairy cows. J. Dairy Res. 71:51-57.

Bobe, G., G. L. Lindberg, A. E. Freeman, and D. C. Beitz. 2007. Short communication: composition of milk protein and milk fatty acids is stable for cows differing in genetic merit for milk production. J. Dairy Sci. 90:3955-3960.

Boldman, K. G., L. A. Kriese, L. D. Van Vleck, C. P. Van Tassell, and S. D. Kachman. 1995. A manual for use of MTDFREML. A set of programs to obtain estimates of variances and covariances [draft]. USDA, ARS, Washington, DC.

DePeters, E. J., J. F. Medrano, and B. A. Reed. 1995. Fatty acid composition of milk fat from three breeds of dairy cattle. Can. J. Dairy Sci. 75:267-269.

Dodenhoff, J., L. D. Van Vleck, S. D. Kachman, and R. M. Koch. 1998. Parameter estimates for direct, maternal, and grandmaternal genetic effects for birth weight and weaning weight in Hereford cattle. J. Anim. Sci. 76:2521-2527.

Edwards, R. A., J. W. B. King, and I. M. Yousef. 1973. A note on the genetic variation in the fatty acid composition of cow milk. Anim. Prod. 16:307-310.

Grummer, R. R. 1991. Effect of feed on the composition of milk fat. J. Dairy Sci. 74:3244-3257.

Henning, D. R., R. J. Baer, A. N. Hassan, and R. Dave. 2006. Major advances in concentrated and dry milk products, cheese, and milk fat-based spreads. J. Dairy Sci. 89:1179-1188.

Karijord, Ø., N. Standal, and O. Syrstad. 1982. Sources of variation in composition of milk fat. Z. Tierzücht. Züchtungsbiol. 99:81-93.

Kelsey, J. A., B. A. Corl, R. J. Collier, and D. E. Bauman. 2003. The effect of breed, parity, and stage of lactation on conjugated linoleic acid (CLA) in milk fat from dairy cows. J. Dairy Sci. 86:2588-2597.

Mensink, R. P., P. L. Zock, A. D. M. Kester, and M. B. Katan. 2003. Effects of dietary fatty acids and carbohydrates on the ratio of serum total to HDL cholesterol and on serum lipids and apolipoproteins: A meta-analysis of 60 controlled trials. Am. J. Clin. Nutr. 77:1146-1155.

Noakes, M., P. J. Nestel, and P. M. Clifton. 1996. Modifying the fatty acid profile of dairy products through feedlot technology lowers plasma cholesterol of humans consuming the products. Am. J. Clin. Nutr. 63:42-46.

O'Donnell, J. A. 1989. Milk fat technologies and markets: A summary of the Wisconsin Milk Marketing Board 1988 Milk Fat Roundtable. J. Dairy Sci. 72:3109-3115.

Palmquist, D. L., A. D. Beaulieu, and D. M. Barbano. 1993. Feed and animal factors influencing milk fat composition. J. Dairy Sci. 76:1753-1771.

Poppitt, S. D., G. F. Keogh, T. B. Mulvey, B. H. McArdle, A. K. H. MacGibbon, and G. J. S. Cooper. 2002. Lipid-lowering effects of a modified butter-fat: A controlled intervention trial in healthy man. Eur. J. Clin. Nutr. 56:64-71.

Rasmussen, B. M., B. Vessby, M. Uusitupa, L. Berglund, E. Pedersen, G. Riccardi, A. A. Rivellese, L. Tapsell, and K. Hermansen. 2006. Effects of dietary saturated, monounsaturated, and n-3 fatty acids on blood pressure in healthy subjects. Am. J. Clin. Nutr. 83:221-226. 
Renner, E., and U. Kosmack. 1974. Genetische Aspekte zur Fettsäurenzusammensetzung des Milchfettes. 2. Fettsäurenmuster der Milch von Nachkommenpopulationen. Züchtungskunde 46:217-226.

Sacks, F. M., and M. Katan. 2002. Randomized clinical trials on the effects of dietary fat and carbohydrate on plasma lipoproteins and cardiovascular disease. Am. J. Med. 113:13S-24S.

SAS Institute. 2002. SAS User's Guide: Statistics. Version 9.1. SAS Institute Inc., Cary, NC.

Soyeurt, H., P. Dardenne, A. Gillon, C. Croquet, S. Vanderick, P. Mayeres, C. Bertozzi, and N. Gengler. 2006. Variation in fatty acid contents of milk and milk fat within and across breeds. J. Dairy Sci. 89:4858-4865.

Syrstad, O., N. Standal, and Ø. Karijord. 1982. Concentration of various fatty acids in milk. Z. Tierzücht. Züchtungsbiol. 99:94100.

Vessby, B., M. Uusitupa, K. Hermansen, G. Riccardi, A. A. Rivellese, L. C. Tapsell, C. Nälsén, L. Berglund, A. Louheranta, B. M. Rasmussen, G. D. Calvert, A. Maffetone, E. Pedersen, I.-B. Gustafsson, and L. H. Storlien. 2001. Substituting dietary saturated for monounsaturated fat impairs insulin sensitivity in healthy men and women: The KANWU study. Diabetologia 44:312-319. 